\title{
Evaluation of Humoral Immunity to Mycobacterium tuberculosis-Specific Antigens for Correlation with Clinical Status and Effective Vaccine Development
}

\author{
Mamiko Niki, ${ }_{1}^{1}$ Maho Suzukawa, ${ }^{2}$ Shunsuke Akashi, ${ }^{2}$ Hideaki Nagai, ${ }^{2}$ Ken Ohta, \\ Manabu Inoue, ${ }^{1}$ Makoto Niki, ${ }^{1}$ Yukihiro Kaneko, ${ }^{1}$ Kozo Morimoto, ${ }^{3}$ Atsuyuki Kurashima, ${ }^{3}$ \\ Seigo Kitada, ${ }^{4}$ Sohkichi Matsumoto, ${ }^{1,5}$ Koichi Suzuki, ${ }^{6}$ and Yoshihiko Hoshino ${ }^{6}$ \\ ${ }^{1}$ Department of Bacteriology, Osaka City University Graduate School of Medicine, Abeno, Osaka 545-8585, Japan \\ ${ }^{2}$ National Hospital Organization, National Tokyo Hospital, Takeoka, Kiyose, Tokyo 204-8585, Japan \\ ${ }^{3}$ Division of Respiratory Medicine, Fukujuji Hospital, Japan Anti-Tuberculosis Association, Matsuyama, Kiyose, Tokyo 204-8522, Japan \\ ${ }^{4}$ National Hospital Organization, National Toneyama Hospital, Toneyama, Toyonaka, Osaka 560-8552, Japan \\ ${ }^{5}$ Department of Infectious Disease Control and International Medicine, Niigata University Graduate School of Medical and \\ Dental Sciences, Niigata 951-8510, Japan \\ ${ }^{6}$ Department of Mycobacteriology, Leprosy Research Center, National Institute of Infectious Diseases, Aoba, Higashimurayama, \\ Tokyo 189-0002, Japan \\ Correspondence should be addressed to Yoshihiko Hoshino; yhoshino@nih.go.jp
}

Received 30 December 2014; Revised 27 February 2015; Accepted 2 March 2015

Academic Editor: Pedro A. Reche

Copyright (C) 2015 Mamiko Niki et al. This is an open access article distributed under the Creative Commons Attribution License, which permits unrestricted use, distribution, and reproduction in any medium, provided the original work is properly cited.

\begin{abstract}
Although tuberculosis remains a major global health problem, Bacille Calmette-Guérin (BCG) is the only available vaccine. However, BCG has limited applications, and a more effective vaccine is needed. Cellular mediated immunity (CMI) is thought to be the most important immune response for protection against Mycobacterium tuberculosis (Mtb). However, the recent failure of a clinical trial for a booster BCG vaccine and increasing evidence of antibody-mediated immunity prompted us to evaluate humoral immunity to Mtb-specific antigens. Using Enzyme-Linked ImmunoSpot and Enzyme-Linked ImmunoSorbent Assays, we observed less correlation of both CMI and IgG titers with patient clinical status, including serum concentration of C reactive protein. However, IgA titers against Mtb were significantly correlated with clinical status, suggesting that specific IgA antibodies protect against Mtb proliferation. In addition, in some cases, IgA antibody titers were significantly associated with the serum concentration of total albumin, which supports the idea that humoral immunity can be influenced by the nutritional status. Based on these observations, we propose that the induction of humoral immunity should be included as an option in TB vaccine development strategies.
\end{abstract}

\section{Introduction}

Tuberculosis (TB) remains a leading cause of death in many regions of the world and one-third of the world's population is thought to be asymptomatic carriers of the causative agent, Mycobacterium tuberculosis (Mtb). The World Health Organization estimates that approximately 8.6 million people contracted the disease and 1.3 million died in 2012 [1]. Bacillus Calmete-Guerin (BCG), the only approved and available TB vaccine, is made using an attenuated strain of Mycobacterium bovis, a relative of Mtb [2]. The primary use of the BCG vaccine is the immunization of children in areas with a high prevalence of TB. However, BCG is considered an inadequate vaccine because it offers no protection for adults [3]. A novel approach is needed to create a more effective vaccine.

Several novel approaches to vaccine production are in development. Recent progress in methods of vaccine development has been covered in several excellent reviews and will not be addressed here $[4,5]$. The majority of these candidate vaccines focus on improving cell-mediated immunity (CMI) to Mtb by modifying the current BCG platform or boosting BCG with a different format, and some candidate vaccines 
TABLE 1: Characteristics of patients in this study.

\begin{tabular}{lcccc}
\hline & Active disease & Past disease & LTBI & Control \\
\hline$n$ & 88 & 84 & 18 & 77 \\
Age $($ mean \pm SD) & $59.9 \pm 20.2$ & $60.5 \pm 19.6$ & $58.8 \pm 17.7$ & $63.9 \pm 10.7$ \\
Age range & $21-97$ & $19-92$ & $21-87$ & $35-87$ \\
Sex (male/female) & $65 / 23$ & $59 / 25$ & $11 / 6$ & $55 / 19$ \\
Positivity of QFT-IT & $69.3 \%$ & $59.5 \%$ & $64.7 \%\left(100 \%^{\mathrm{a}}\right)$ & ND \\
\hline
\end{tabular}

${ }^{a}$ Patients were all positive for any IRGA (QFT-GIT and/or ELISPOT IFN- $\gamma$ ). ND: not done.

have shown promise in mice and/or nonhuman primates [6, 7]. Modified Vaccinia Ankara (MVA) $85 \mathrm{~A}$ is one of the more advanced vaccine candidates that use BCG with a booster of Mtb major secreted antigen complex 85A (Ag85A) [8], which boosts BCG-primed Th1 immune responses. It was expected that MVA85A would reduce the incidence of TB cases in an endemic area (i.e., South Africa) by $60 \%$. However, the phase $2 \mathrm{~b}$ clinical trial found that MVA85A conferred no detectable improvement against Mtb infection [9].

Although CMI has been established as a major component in the control of mycobacterial infections, serology analyses indicate that Mtb infection also induces humoral immune responses against various mycobacterial antigens [10]. In addition, BCG vaccination can induce antibody responses to several mycobacterial antigens [11-13], which elicits both innate and cell-mediated immunity against mycobacteria [13]. Humoral immunity could modify the fate of intracellular bacteria through mechanisms ranging from simple opsonization to complicated FcR activation [14].

The consensus for many years was that the control of vigorous granuloma formation following infection by pathogenic fungi (i.e., intracellular pathogens) was achieved by activating CMI, while humoral immunity was believed to have no role in protection. However, recent studies using hybridoma technology found protective monoclonal antibodies against numerous pathological fungi [15]. Two ongoing vaccine trials for the fungus Candida albicans, a major human pathogen, are expected to transduce protection by inducing antibody-mediated immunity [16].

These studies suggest that humoral immunity might also play an important role in protection against Mtb infection, a function which could be used to develop a new technology for more effective vaccine development. To evaluate the feasibility of using humoral immunity against mycobacterial antigens for effective vaccine development, we compared IgG and IgA antibody titers using a variety of clinical and immunological parameters. The results suggest that $\operatorname{IgA}$ antibodies against Mtb components would make suitable Mtb vaccine candidates.

\section{Subjects and Methods}

2.1. Participants. Patients of National Tokyo Hospital, Tokyo, Japan, were consecutively enrolled in the study, after giving informed consent, from May 2010 through May 2011. A total of 190 Japanese patients (age: $60.1 \pm 19.6 \mathrm{yr}$, male: $71.1 \%$ ) were recruited. The following information was obtained from all patients at the time of enrollment: history of prior TB disease, work history in any healthcare setting or recent exposure to a patient with active $\mathrm{TB}$, and other TB risk factors such as having immunodeficiency disorders or taking immunosuppressive drugs [17]. We used the same inclusion/exclusion criteria as in a previous study [18]. Information on previous medical history, clinical signs and symptoms, and radiological and microbiological data including the values of serum $C$ reactive protein (CRP) and the concentration of total albumin were also collected. The patients were then divided into three categories: (1) Active disease: patients having positive TB symptom(s) and positive smear results and/or positive demonstration of Mtb in culture; (2) Past disease: previously diagnosed with $\mathrm{TB}$, treated and currently free from symptom(s); and (3) Latent TB infection (LTBI): no symptoms with normal chest $\mathrm{X}$-ray, but having positive results from an interferon gamma release assay (IGRA). Among the 190 patients recruited, 88 (46\%) were classified as "Active disease," 84 (45\%) as "Past disease," and 18 (9\%) as LTBI. We enrolled age- and gender-matched patients with respiratory disease who were confirmed not to have any mycobacterial diseases as negative controls. All medical, radiological, and microbiological information was collected to confirm their eligibility. A total of 77 Japanese adults (age: $63.9 \pm 10.7 \mathrm{yr}$, male: $71.4 \%$ ) were recruited as a control group (Table 1). In Japan, more than $90 \%$ of the population has been vaccinated with BCG since 1929 , suggesting that most of the control group have received the BCG vaccine. The research protocol was approved by the Institutional Review Boards of Osaka City University Graduate School of Medicine, Osaka, Japan, National Tokyo Hospital, Tokyo, Japan, Fukujuji Hospital, Tokyo, Japan, and National Toneyama Hospital, Osaka, Japan, and by the Research Ethics Committee of the National Institute of Infectious Disease, Tokyo, Japan.

2.2. Evaluation of Clinical Status. The clinical status of patients with active disease was evaluated as previously described with modification [19] (see Supplemental Table 1 in Supplementary Material available online at http://dx.doi.org/ 10.1155/2015/527395). (1) "Smear at entry" (entry = point of diagnosis before treatment): sputum smear taken at entry was stained and inspected by microscopy. The severity was subdivided as 0 (no acid fast bacilli (AFB) on smear), \pm (1-2 AFB per 300 field), 1+ (1-9 AFB per 100 field), 2+ (more than 10 AFB per 100 field), and 3+ (more than 10 AFB per field). (2) "Positive conversion time": duration (weeks) between entry and positive MGIT results. (3) Duration of culture negative: 
time (days) from initiation of treatment to negative smear results ( 0 AFB per field) by sputum microscopy. (4) Several routine laboratory tests including serum concentration of " $\mathrm{C}$ reactive protein (CRP) at entry," (total) "Albumin at entry," and "CRP after 60 days of treatment" were simultaneously performed. (5) Severity of chest radiography at entry: "The Japanese Society for Tuberculosis Classification" (1959) was applied [20]. Briefly, tuberculosis lesions are classified by chest X-ray findings as type (cavity) and extent. "X-ray type (cavity)" was subdivided from III to I (III: no cavity, II: morbid foci other than I, and I: widespread cavities) and "X-ray extent" from 1 to 3 (1: minimal, 2: moderate, and 3: severe). These markers and classifications were chosen because serum albumin levels reaction to the tuberculin skin test, the Gaffky scale, and negative conversion time are significantly correlated with both type and extent [20]. If patients contracted hilar glandular tuberculosis and/or tuberculosis lymphadenopathy, the evaluation of (1), (2), and (3) was excluded and that of (4) and (5) was included for the analysis because bacterial presentation in the sputum is rare.

2.3. QuantiFERON-TB Gold In-Tube (QFT-GIT) Assay. The QFT-GIT assay was performed using fresh whole blood in accordance with the manufacturer's instructions (Cellestis, Chadstone, Australia). The results were interpreted with software provided by Cellestis. The antigen used in this assay is the $6 \mathrm{kDa}$ early secreted antigenic target from $M$. tuberculosis (ESAT-6), the $10 \mathrm{kDa}$ culture filtrate protein (CFP-10), and TB7.7. However, there was no response to TB7.7 in Japanese patients [17]. Results were scored as "positive" when the IFN- $\gamma$ concentration in the tube with TB-specific antigen was $>0.35 \mathrm{IU} / \mathrm{mL}$, after subtracting the value of the nil control, and at least $>25 \%$ of the negative control value. When the net IFN- $\gamma$ response was $<0.35 \mathrm{IU} / \mathrm{mL}$ for the antigens and the response to the mitogen-positive control was $>0.5 \mathrm{IU} / \mathrm{mL}$, the response was considered "negative" $[17,19]$. Stimulation with mitogen induced more than $0.5 \mathrm{IU} / \mathrm{mL}$ in all subjects, supporting the contention that immunosuppressed participants were not included in the study (data not shown).

2.4. ELISPOT Assay. The IFN- $\gamma$ ELISPOT assay was performed as previously described [17]. Briefly, peripheral blood mononuclear cells (PBMCs) were seeded in precoated IFN- $\gamma$ ELISPOT plates (Becton, Dickinson and Company, Franklin Lakes, NJ, USA) with $2.5 \times 10^{5}$ cells per well in AIM-V medium (GIBCO) and incubated with a protein $(10 \mu \mathrm{M})$ of each antigen at $37^{\circ} \mathrm{C}$ in $5 \% \mathrm{CO}_{2}$ for $16 \mathrm{hr}$. A negative control (no mitogen or antigen) and a positive control (phytohemagglutinin, PHA, $5 \mu \mathrm{g} / \mathrm{mL}$ ) were also included. After incubation, the wells were washed and developed with a conjugate against the antibody used and an enzyme substrate. Spot-forming units were counted using a KS ELISPOT imaging system (Carl Zeiss, Hallbergmoos, Germany) and labeled spot-forming cells (SFC). ELISPOT results were interpreted according to the following criteria: the test result was positive when (1) the negative control had 0-5 spots and (2) the spot count (negative control spot count) was greater than six. The test result was negative when the above criteria were not met and the positive control was valid $(\geq 20)[17,21]$. Data were plotted as the numbers of SFC/ $1 \times 10^{6}$ cells.

2.5. ELISA Assay. Concentrations of IgG and IgA antibodies against Mtb were determined by ELISA using recombinant proteins as previously described, with modification [22]. Ninety-six well microplates (Sumilon Type H, LMS, Tokyo, Japan) were coated with each recombinant antigen in bicarbonate buffer, $\mathrm{pH} 9.6$ overnight at $4^{\circ} \mathrm{C}$ (Supplemental Table 2). The plates were blocked with phosphate buffered saline (PBS) containing $0.05 \%$ Tween 20 and $5 \%$ skim milk for $12 \mathrm{hr}$ at $4^{\circ} \mathrm{C}$ and washed four times with PBS containing $0.05 \%$ Tween 20. Human serum samples diluted $1: 200$ (for IgG) or $1: 100$ (for IgA) in PBS containing 0.05\% Tween 20 and 0.5\% skim milk were then added in duplicate (IgG) or triplicate (IgA) to the antigen-coated wells and incubated for $12 \mathrm{hr}$ at $4^{\circ} \mathrm{C}$. After washing the wells, HRP-conjugated antihuman IgG or IgA antibodies were added at a 1:2000 or 1:1000 dilution, respectively. Following a one $\mathrm{hr}$ incubation at $37^{\circ} \mathrm{C}$, the plates were washed four times before $100 \mu \mathrm{L}$ of SureBlue reserveTMB was added to each well. The reactions were stopped after 10 min by adding $50 \mu \mathrm{L}$ of $0.1 \mathrm{M} \mathrm{HCl}$, and absorbance was measured at $450 \mathrm{~nm}$ using a Multiskan Spectrophotometer (Thermo Fisher Scientific, Yokohama, Japan). The results of the IgG-ELISA were expressed as absorbance at $450 \mathrm{~nm}$, whereas results of the IgA-ELISA were expressed as ELISAIndex, $S /(B+3 S D)[23,24]$, where $S$ is the average OD value of the duplicate test samples and $B+3 \mathrm{SD}$ corresponds to the average OD value of the duplicate negative controls $(B)$ plus three times the standard deviation (SD).

2.6. Reagents and Recombinant Protein Preparation. pET-21b, pET-22b, and Bugbuster HT were obtained from Novagen (Darmstadt, Germany); Escherichia coli BL21 (DE3) cells were from Toyobo (Osaka, Japan); Lowenstein-Jensen LuriaBertani medium and carbenicillin were from Sigma (St. Louis, MO, USA); isopropyl-1-thio-beta-d-galactopyranoside and Ni-NTA agarose were from Qiagen (Gaithersburg, MD, USA); skim milk was from Morinaga (Tokyo, Japan); horseradish peroxidase-conjugated antihuman IgG or IgA antibodies and Envision kits were from Dako (Carpinteria, CA, USA); SureBlue reserve TMB microwell peroxidase substrate was from KPL (Gaithersburg, MD, USA); and monoclonal Acr antibody was from HyTest (Turku, Finland).

A pET-21b or pET-22b-based vector expressing $16 \mathrm{kDa}$ $\alpha$-crystallin homolog (Acr, $16 \mathrm{kDa}$ protein, hspX or TB16.3: Rv2031c), Ag85A (Rv3804c), CFP-10 (Rv3874), ESAT-6 (Rv3875), heparin-binding haemagglutinin adhesin (HBHA: Rv0475), heat-stress-induced ribosome binding protein A (HrpA, $20 \mathrm{kDa}$ protein, Acr2 or hsp20: Rv0251c), and mycobacterial DNA-binding protein 1 (MDP1: Rv2986c) were produced by a PCR-based approach using a bacterial chromosome. Each PCR product containing coding regions was designed to allow expression of C-terminal, 6 histidinetagged variants of the recombinant proteins following ligation into $\mathrm{pET}-2 \mathrm{~b}$. After construction, expression vectors were confirmed by DNA sequencing. Recombinant Mtb proteins were purified using Ni-NTA columns $(1 \mathrm{~mL}$ bed 
volume, GE Healthcare, Piscataway, NJ, USA) according to the manufacturer's instructions. Purified proteins were used as mycobacterial antigens for ELISAs and ELISPOT assays.

2.7. Statistical Analysis. The Mann-Whitney $U$ test was used to compare IgG and IgA levels between two independent groups, whereas one-way ANOVA was used for the comparison of three or more unmatched groups. Spearman's rank correlation coefficient was used to determine the correlation between ELISA values and the severity of clinical status values. Pairwise comparisons were made between areas under the receiver operating characteristic curve (AUROC) for the categorized groups. Optimal cut-off values were chosen when Youden's index (sensitivity and specificity 1) was maximal. All analyses were performed using online statistics calculators (http://www.socscistatistics.com/tests/ Default.aspx, http://vassarstats.net/index.html, http://molpath.charite.de/cutoff/index.jsp). The threshold of significance was set at $P<0.05$.

\section{Results}

3.1. Antibody Titers in Active Disease, Past Disease, LTBI Cases, and Controls. Titers of IgG and IgA antibodies against recombinant mycobacterial antigens were measured separately in the sera of "Active disease" $(n=88)$, "Past disease" $(n=84)$, LTBI $(n=18)$ cases, and control $(n=77)$. We chose mycobacteria-specific antigens based on (1) proteome analysis of antibody responses to $\mathrm{Mtb}$ from active TB patients (included Acr, Ag85, CFP-10, and HrpA) [25, 26]; (2) in silico studies performed to identify TB vaccine candidates (included Acr, Ag85, and ESAT-6) [27]; and (3) publications identifying HBHA and MDP1 as mycobacteriaspecific antigens [22, 28, 29]. Active disease patients had higher levels of IgG antibodies against all antigens tested compared to controls. In particular, significant increases in serum IgG levels were observed against ESAT-6, CFP-10, Acr, HBHA, and HrpA (Figure 1). Titers of past disease were lower than those of active disease except for MDP1, Ag85A, and HrpA (Figure 1). In contrast, IgA antibody titers for MDP1 and HrpA were higher in the control group than in the active disease group (Figure 2). The individual values of antibodies against the seven antigens were used to generate receiver operating characteristic curves (ROC). The Area under the ROC curves (AUROC) was calculated in both Tables 2 and 3.

\subsection{ELISPOT and QFT Titers in Active Disease, Past Disease, and LTBI and Comparison between CMI Assays and Humoral ELISA Assays. CMI against various recombinant antigens was measured by ELISPOT assay for the active disease, past disease, and LTBI groups. Ninety-six participants (age: $58.6 \pm$ $18.9 \mathrm{yr}$, male: $68.8 \%$ ) were randomly chosen for the analysis of IFN- $\gamma$ ELISPOT assay for ESAT- 6 and CFP-10 antigens. A portion of the participants were also randomly recruited for the ELISPOT assay (MDP1: $n=37$ (age: $55.9 \pm 18.2 \mathrm{yr}$, male: 67.6\%); Acr: $n=36$ (age: $55.7 \pm 18.4$ yr, male: 66.7\%); HBHA: $n=20$ (age: $56.2 \pm 17.7 \mathrm{yr}$, male: $100 \%$ ); and HrpA: $n=29$ (age: $56.7 \pm 16.8 \mathrm{yr}$, male: 100\%)).}

No significant difference was observed in CMI, except for MDP1, in which past disease and LTBI patients had significantly more SFCs than active disease patients (Figure 3). Stimulation with PHA induced more than 80 SFC per $1 \times$ $10^{6}$ cells in all subjects (data not shown), indicating the lack of immunosuppressed participants in the study. When the results from CMI (ELISPOT) and humoral immunity (ELISA to $\operatorname{IgG}$ and $\operatorname{IgA}$ ) were compared, there was no association between ELISPOT positivity and the values of IgG or IgA (Supplemental Figure 1). Also, there were no significant differences in the values of QFT-GIT assay among the active disease, past disease, and LTBI groups (Supplemental Figure 2).

\section{3. "CRP at Entry" as a Surrogate Marker of Other Clinical} Markers. We divided serum CRP values at entry into two categories: $\mathrm{CRP}<2 \mathrm{mg} / \mathrm{mL}$ (negative or minimal inflammation) and $\mathrm{CRP} \geq 2 \mathrm{mg} / \mathrm{mL}$ (intermediate or severe inflammation) because CRP is a more sensitive inflammation marker than erythrocyte sedimentation rate, another systemic inflammation marker. Other clinical markers were also divided into several categories (from negative to severe, Supplemental Table 1). All other clinical markers, such as "Smear at entry," "Positive conversion time," "Duration of culture negative," "Albumin at entry," "CRP at the time after 60 days," "X-ray type (cavity)," and "X-ray extent" were evaluated with the scores of "CRP at entry" (Figure 4). The "Smear at entry" $(r=0.296, P<0.05)$, "Duration of culture negative" $(r=$ $0.391, P<0.01)$, "Albumin at entry" $(r=0.687, P<0.01)$, "CRP after 60 days" $(r=0.528, P<0.01)$, "X-ray type (cavity)" ( $r=0.271, P<0.05)$, and "X-ray extent" $(r=$ $0.445, P<0.01)$ scores were significantly associated with those of "CRP at entry," suggesting that "CRP at entry" could serve as a surrogate for other clinical markers. Only "Positive conversion time" was not associated with "CRP at entry" ( $r=$ $0.09, P=0.45$, data not shown).

3.4. Reverse Association between IgA Titers against HrpA and "CRP at Entry". Finally, we compared the results of immunological scores and clinical scores, such as "Smear at entry," "Positive conversion time," "Duration of culture negative," "CRP at entry," "Albumin at entry," "CRP at the time after 60 days," "X-ray type (cavity)," and "X-ray extent." There was no association among IgG antibodies. Among IgA antibodies, "CRP at entry" was significantly associated with HrpA IgA levels $(r=-0.2505, P<0.05)$; ESAT-6 IgA was significantly associated with "Albumin at entry" $(r=0.3304$, $P<0.01$ ); and Acr IgA was also associated with "Albumin at entry" ( $r=0.3334, P<0.01)$ (Figure 5). No association was found between immunological markers and clinical markers for other measured parameters (Supplemental Figures 3-10 and data not shown).

\section{Discussion}

We compared serum antibody titers and IGRA against components of Mtb to evaluate humoral and cell-mediated immunity for improvements in vaccine development. We also 

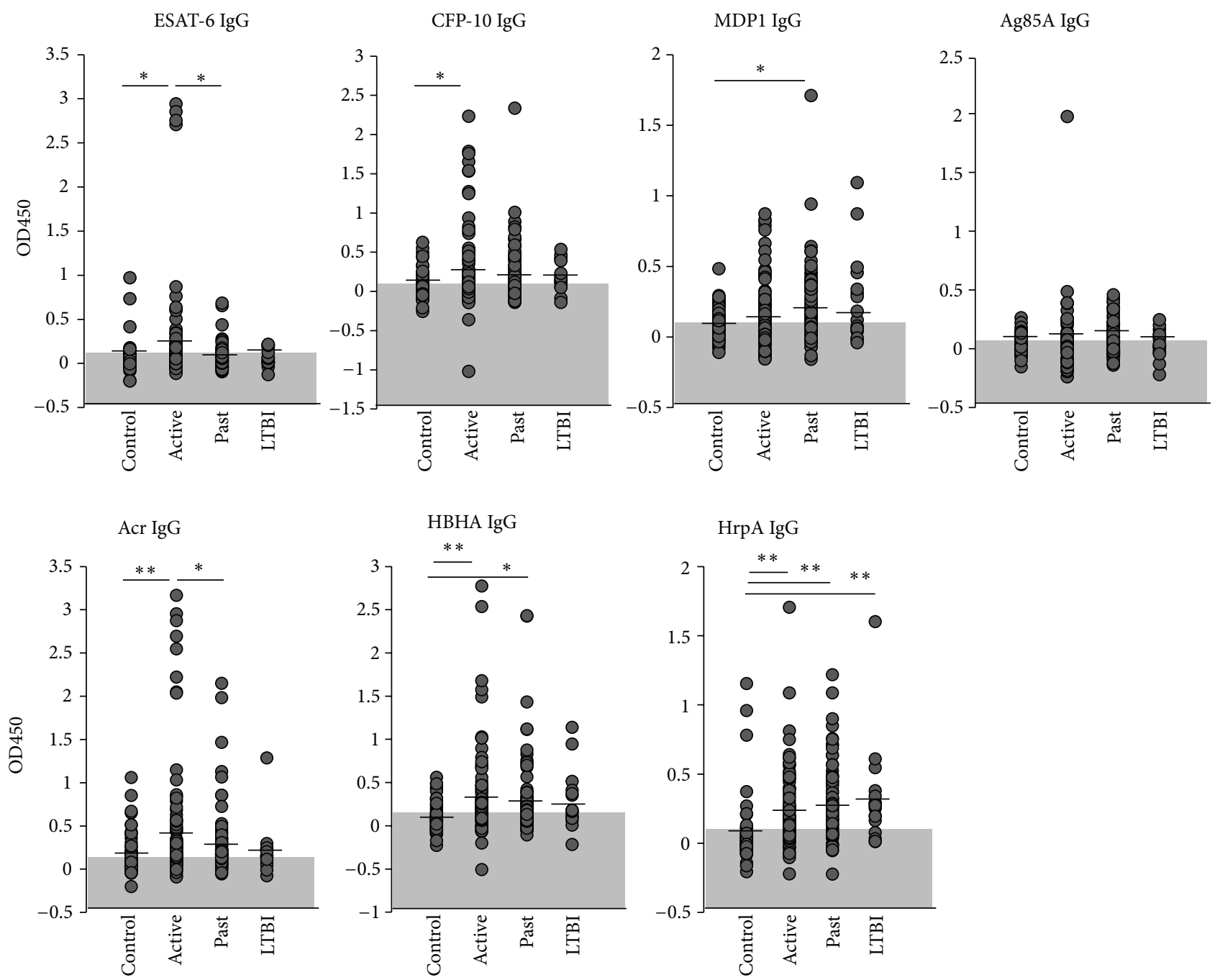

Figure 1: IgG responses to Mtb antigens. The levels of serum IgG against 7 antigens (ESAT-6, CFP-10, MDP1, Ag85A, Acr, HBHA, and HrpA) in active disease (labeled as "Active"), past disease ("Past"), latent TB infection ("LTBI"), and controls ("Control") were analyzed by ELISA. Data shown are the average of triplicate experiments. Shaded areas: areas under cut-off values, vertical lines: mean values, ${ }^{*} P<0.05$, ${ }^{* *} P<0.01$.

compared these data with several clinical indices to evaluate a possible link for disease progression. Some IgA titers were elevated in the controls and lower in the active disease group. "CRP at entry" was significantly associated with several other clinical parameters. IgA antibody levels against HrpA in active disease patient were significantly associated with the clinical inflammation status measured by "CRP at entry." In addition, IgA antibodies against ESAT- 6 and Acr were significantly associated with clinical nutrition status as measured by "Albumin at entry." Notably, an inverse correlation was found between "CRP at entry" and the IgA titer for HrpA, and a positive correlation was revealed between "Albumin at entry" and IgA titers for ESAT- 6 and Acr. These findings suggest that some IgA antibodies targeting mycobacterial antigens can protect against the bacterial expansion or replication and corresponding lung inflammation previously reported in murinestudies in vivo $[23,30-32]$ and that antibody production could be influenced by the nutritional status of the patients, as has been reported in many studies [33-36].

CMI induction of the Th1 response should be the center of the principal immunity to Mtb infection. However, a recent study revealed this is not always the case. Strong immunological pressure on microbes usually drives an antigen shift, whereas a whole genome analysis of human $\mathrm{T}$ cell epitopes of Mtb showed they are evolutionarily hyperconserved [37]. If humans eliminate Mtb primarily through CMI, bacterial antigens might be exposed by the high level of immunological pressure; therefore, the epitopes should be hypermutated as they are in other pathogens such as hepatitis B virus, hepatitis C virus, HIV, or influenza virus [38-41]. We also found that most CMI measured by IFN- $\gamma$ ELISPOT showed no difference among active, past, and LTBI patients. In addition, the frequency of IL-17+ CD4 cells (Th17 cells) was increased in HBHA or MDP1 responded populations in active or 

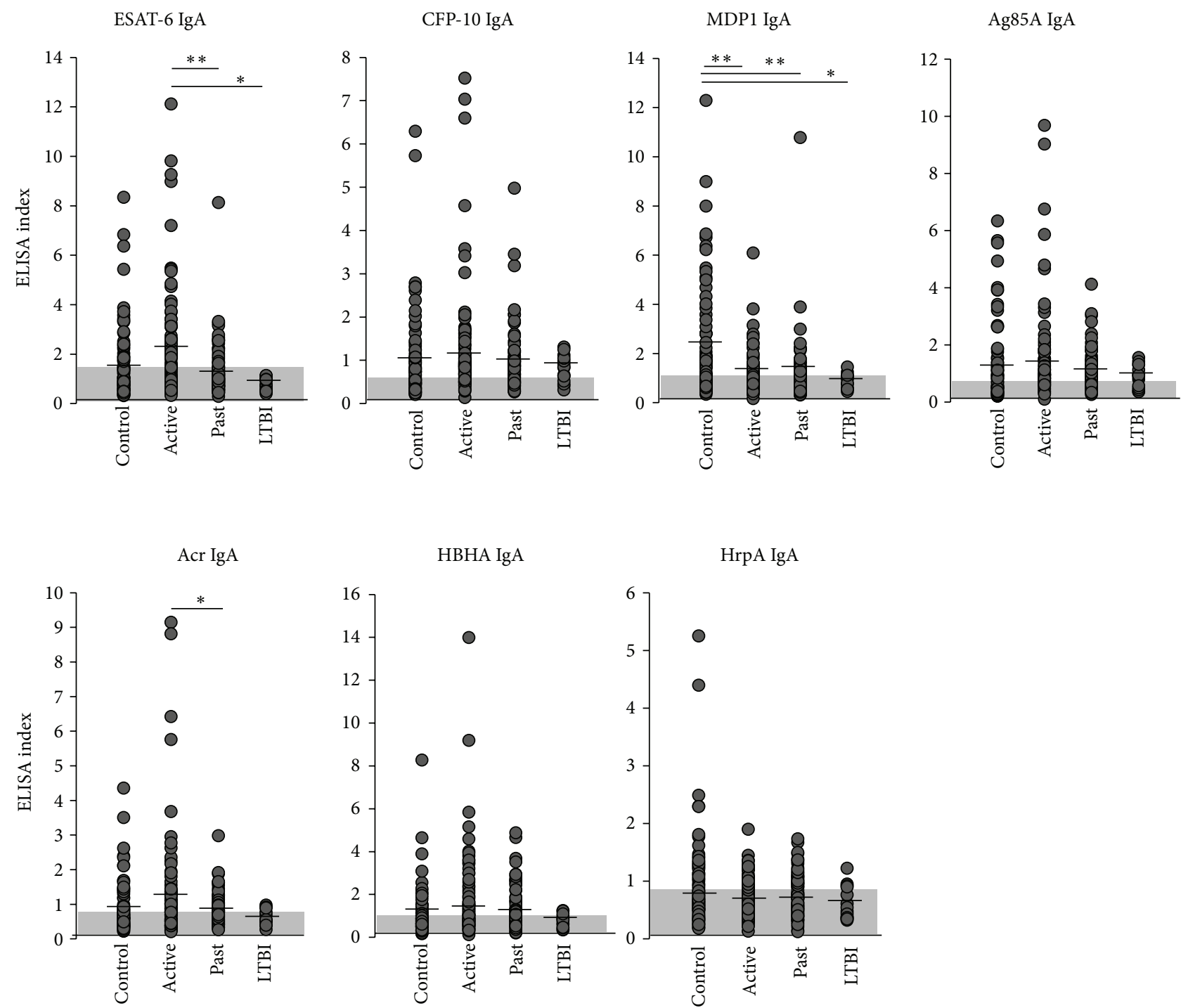

Figure 2: IgA responses to Mtb antigens. The levels of serum IgA against 7 antigens (ESAT-6, CFP-10, MDP1, Ag85A, Acr, HBHA, and HrpA) in active disease (labeled as "Active"), past disease ("Past"), latent TB infection ("LTBI"), and controls ("Control") were analyzed by ELISA. Data shown are the average of triplicate experiments. Shaded areas: areas under cut-off values, vertical lines: mean values, ${ }^{*} P<0.05$, ${ }^{* *} P<0.01$.

past TB patients [28]. These observations led us to initiate the present study in order to examine the possibility of an additional immune response to mycobacterial infection.

Our study of cellular gene expression, derived by bronchoalveolar lavage (BAL) in active TB patients as well as normal volunteers using DNA microarray analysis, indicated a shift from a Th2 to Th1 phenotype in lung immune cells during the course of tuberculosis [42]. Most of the BAL cells from active patients showed a Th1 phenotype whereas all normal volunteers and some TB patients were Th2. Notably, the phenotype shifted from Th2 to Th1 in a patient during the course of the disease, supporting the premise that humoral immunity is predominant in the early stage of infection [16]. This observation suggests that humoral immunity might be an effective target for adjuvant enhancement in a new TB vaccine.
Recent studies have revealed that approximately $10 \%$ of bacterial proteomes could generate a human antibody response and a much smaller fraction of antigens (estimated as less than $1 \%$ ) could be preferentially recognized by serum antibodies in active TB patients $[25,26]$. We noted that the titers of some IgA antibodies were lower in active TB patients than in the controls, suggesting that BCG-induced humoral immunity to $\mathrm{Mtb}$ is maintained even after adolescence, but active disease can occur when the immunity diminishes. Several studies have also confirmed that vaccination with specific Mtb antigens such as Acr, Ag85, CFP-10, ESAT-6, or HBHA efficiently induces IgA and/or IgG antibodies as well as IFN- $\gamma$ and other cytokines [35-40]. It is possible that DNA vaccination can induce humoral immunity in addition to CMI, which is important in protecting against the growth of Mtb. [30-32, 43-49]. 


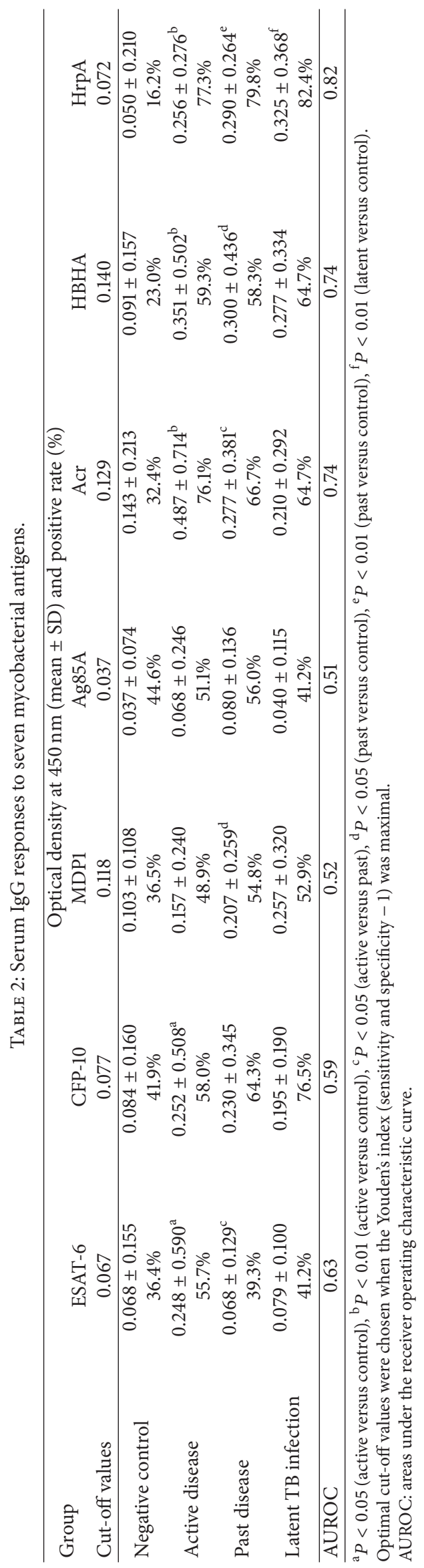




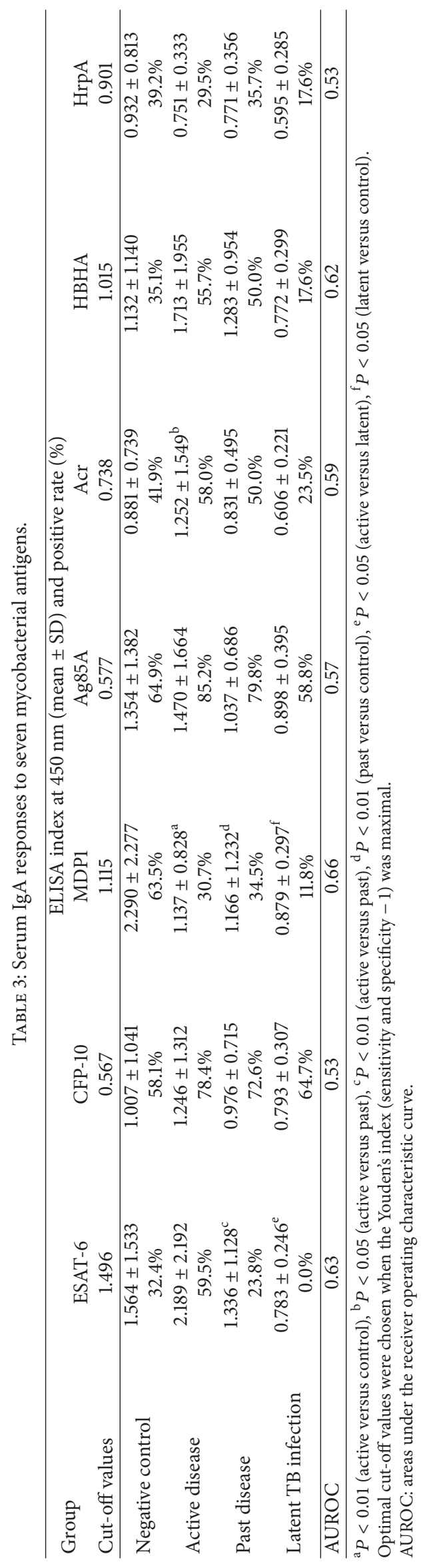



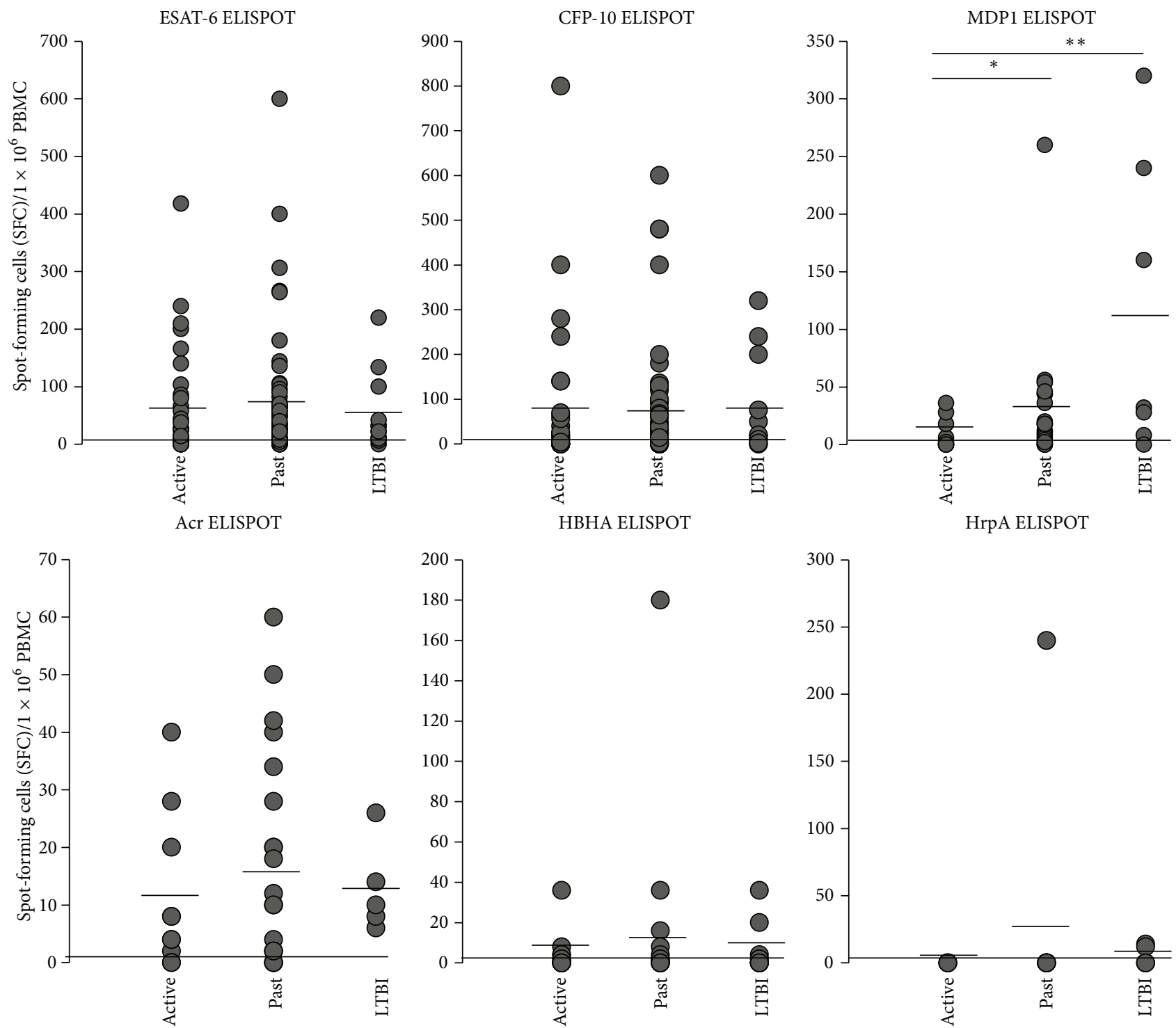

FigURE 3: ELISPOT responses to Mtb antigens. ELISPOT SFCs against 6 antigens (ESAT-6, CFP-10, MDP1, Acr, HBHA, and HrpA) in active disease (labeled as "Active"), past disease ("Past") and latent TB infection ("LTBI"). Data shown are the average of triplicate experiments. Vertical lines: mean values, ${ }^{*} P<0.05,{ }^{* *} P<0.01$.

There are many reports analyzing the level of IgG antibody titers in different clinical stages of TB [22, 50-52]. The major conclusion of these studies is that most IgG antibodies increase in the active phase and decline following treatment or during a LTBI, suggesting that the bacterial load is associated with the production of IgG and that the clinical cure lowers immunoglobulin levels. In this study, we confirmed that Mtb-specific IgG antibody levels are associated with bacterial load, because most IgG values were higher in active patients than past patients. However, we noted that IgA antibody titers of HrpA and MDP1 were quite different from those of IgG antibodies as they were higher in controls than in active patients. These results suggest that IgA levels toward some Mtb antigens are modified after infection, even if the patients had previously received a BCG vaccination as most Japanese should. Based on these findings, it can be hypothesized that a decline in IgA levels for these antigens, which is initially induced by BCG vaccination, might be related to bacterial growth. Although the DNA sequence of these antigens is almost homologous between BCG and Mtb (Supplemental Table 3), there may be a difference in protein structure and/or an amino acid sequence that is essential for the induction of humoral immune responses.

Both Acr and HrpA are mycobacterial heat shock proteins or chaperones that were revealed by a whole genome analysis of $\mathrm{H} 37 \mathrm{Rv}$ [53]. Acr is a well characterized mycobacterial protein that possesses immune-dominancy $[31,32,48,54$, 55]. Acr plays important roles during log phase growth and transition to the stationary phase of Mtb proliferation $[56,57]$. Moreover, there are some studies concluding that monoclonal IgA antibody against Acr protects mycobacterial proliferation in vivo. Williams et al. compared the effect of 


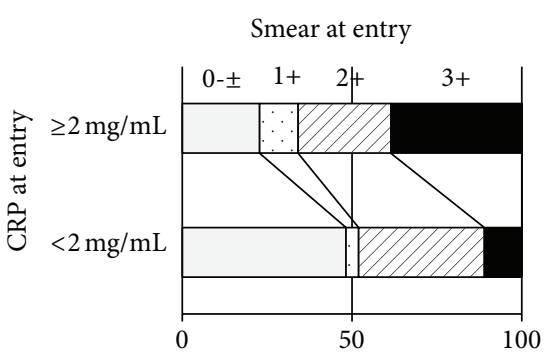

(\%)

CRP after 60 days $(\mathrm{mg} / \mathrm{mL})$

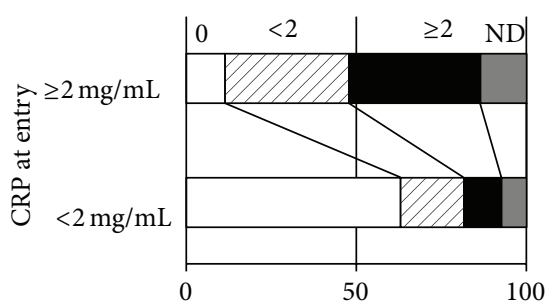

(\%)
Duration culture negative (days)

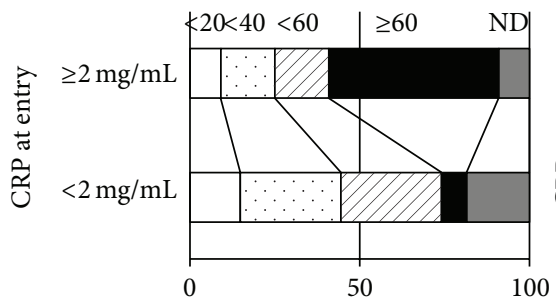

(\%)

$\mathrm{X}$-ray type (cavity)

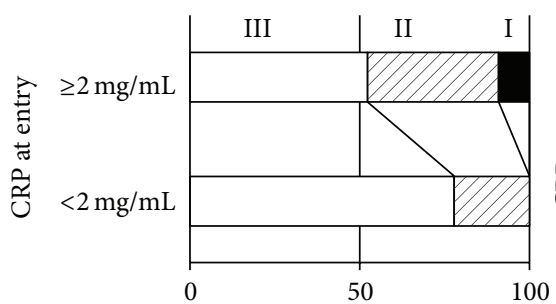

(\%)
Albumin at entry $(\mathrm{g} / \mathrm{mL})$

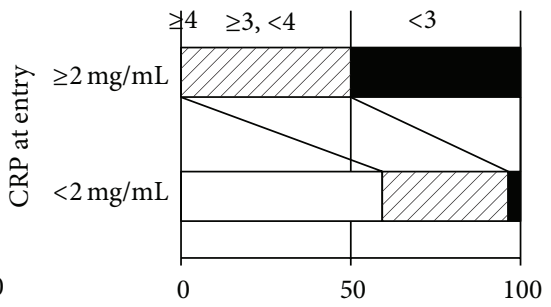

(\%)

X-ray extent

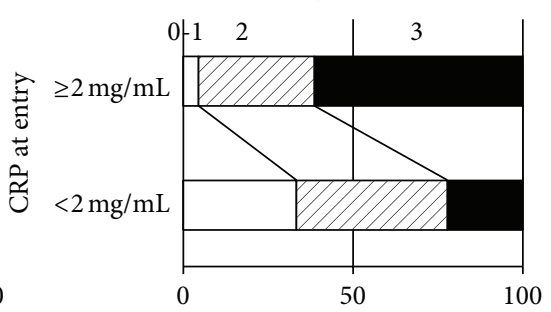

(\%)

FIGURE 4: Clinical markers evaluated with "CRP at entry." All markers were significantly associated with "CRP at entry." "CRP at entry" was significantly associated with "Smear at entry" $(r=0.296, P<0.05)$, "Duration of culture negative" $(r=0.391, P<0.01)$, "Albumin at entry" $(r=0.687, P<0.01)$, "CRP at 60 days" after treatment $(r=0.528, P<0.01)$, X-ray type (cavity) $(r=0.271, P<0.05)$, and X-ray extent $(r=0.445, P<0.01)$.
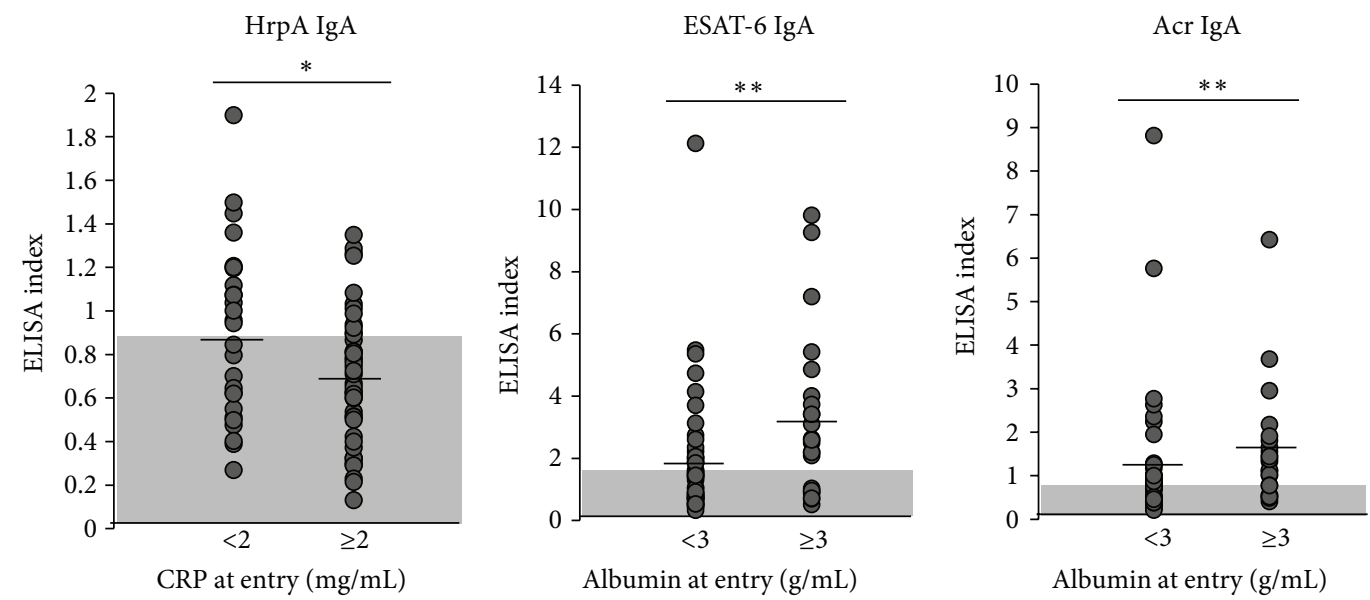

FIGURE 5: Association between immunological scores and clinical scores. HrpA IgA was negatively associated with "CRP at entry." ESAT-6 IgA and Acr IgA were positively associated with "Albumin at entry." Shaded areas: areas under cut-off values, vertical lines: mean values. ${ }^{*} P<0.05,{ }^{* *} P<0.01$.

TBA61 (anti-Acr monoclonal IgA) and TBA68 (IgG of the same epitope as TBA61) on Mtb growth and observed that IgA antibody contributed more to a reduction in the number of bacteria in mouse lung space [31]. López et al. reported a greater reduction of bacteria and pathological severity of the disease when using TBA 61 compared with TBA84 (IgA to PstS-1, $38 \mathrm{kDa}$ secreted glycoprotein [58, 59]) [32]. Although these experiments were performed using mouse models, they suggested that humoral immunity could at least modify or reduce the growth of Mtb [31, 32]. HrpA was identified by Ohara et al. in 1997 [60] with a 30\% homology to Acr, which increases to $40 \%$ when comparing Acr core residues [61]. It was later demonstrated that the expression of HrpA is upregulated by heat-shock, nitrate, or macrophage engulfment, suggesting that HrpA is one of the early immune targets of Mtb antigens [62]. We found that the IgA to Acr or HrpA was associated with some of the parameters used to measure the clinical status of active patients and that it could support inhibition of the mycobacterial burden.

We also revealed that "CRP at entry" is a good surrogate marker for other clinical markers, a finding which is consistent with reports of previous studies [63]. Hypoalbuminemia has emerged as an independent factor of poor prognosis in several studies [33-36]. In this study, IgA antibody titers 
generated by certain Mtb-specific antigens were significantly correlated with the scores of clinical markers such as CRP or albumin levels at first admission, which appears to be one of the host immune responses against Mtb. There was a significant association between IgA antibody titer and albumin. The importance of nutritional status for the clinical manifestation of TB has been evidenced by the fact that the incidence of TB is much higher in developing countries. This position is also supported by the correlations of serum IgA titers and higher albumin levels in the present study. The fact that humoral immunity had no association with CMI suggests that mycobacterial antigens influence humoral and cellular mediated immunity by different mechanisms. These findings suggest that induction of the IgA response could be a good strategy for Mtb vaccine design.

\section{Conclusion}

IgA antibody titers against several Mtb antigens, but not IgG antibodies nor CMI, significantly correlate with the clinical status of $\mathrm{TB}$ patients, raising the possibility that specific IgA antibodies protect against promotion of Mtb. These observations also suggest that induction of humoral immunity, especially for the IgA response, should be included as an option for $\mathrm{TB}$ vaccine strategies.

\section{Conflict of Interests}

The authors declare that they have no conflict of interests.

\section{Authors' Contribution}

Mamiko Niki, Manabu Inoue, Makoto Niki, and Yoshihiko Hoshino performed the laboratory experiments. Maho Suzukawa, Shunsuke Akashi, Hideaki Nagai, Kozo Morimoto, Atsuyuki Kurashima, Seigo Kitada, and Sohkichi Matsumoto contributed to the experimental system and statistical analysis. Mamiko Niki, Sohkichi Matsumoto, and Yoshihiko Hoshino contributed to the planning and proposal of the work. Yukihiro Kaneko, Ken Ohta, Koichi Suzuki, and Yoshihiko Hoshino coordinated the work.

\section{Acknowledgments}

The authors are thankful to all healthcare workers and tuberculosis patients who participated in this study. Sincere appreciation goes to Ms. Ayako Watanabe and Ms. Yasuko Inoue for their assistance with the laboratory assays. This work was supported in part by a Grant-in-Aid for Research on Emerging and Reemerging Infectious Diseases from the Ministry of Health, Labour and Welfare of Japan for $\mathrm{H}$. Nagai, S. Matsumoto, and Y. Hoshino, by a Grant-in- Aid for Scientific Research (B) and (C) from the Japan Society for the Promotion of Science for S. Matsumoto and Y. Hoshino, and by a Grant-in-Aid for Adaptive and Seamless Technology transfer Program from Japan Science and Technology Agency for S. Matsumoto.

\section{References}

[1] WHO, Global Tuberculosis Report 2013, 2013, http://www.who .int/tb/publications/global_report/en/.

[2] P. E. M. Fine, "Variation in protection by BCG: implications of and for heterologous immunity," The Lancet, vol. 346, no. 8986, pp. 1339-1345, 1995.

[3] B. B. Trunz, P. Fine, and C. Dye, "Effect of BCG vaccination on childhood tuberculous meningitis and miliary tuberculosis worldwide: a meta-analysis and assessment of costeffectiveness," The Lancet, vol. 367, no. 9517, pp. 1173-1180, 2006.

[4] T. H. M. Ottenhoff and S. H. E. Kaufmann, "Vaccines against tuberculosis: where are we and where do we need to go?" PLoS Pathogens, vol. 8, no. 5, Article ID e1002607, 2012.

[5] P. Andersen and S. H. E. Kaufmann, "Novel vaccination strategies against tuberculosis," Cold Spring Harbor Perspectives in Medicine, vol. 4, no. 6, 2014.

[6] C. Aagaard, T. Hoang, J. Dietrich et al., "A multistage tuberculosis vaccine that confers efficient protection before and after exposure," Nature Medicine, vol. 17, no. 2, pp. 189-195, 2011.

[7] P. L. Lin, J. Dietrich, E. Tan et al., "The multistage vaccine $\mathrm{H} 56$ boosts the effects of BCG to protect cynomolgus macaques against active tuberculosis and reactivation of latent Mycobacterium tuberculosis infection," The Journal of Clinical Investigation, vol. 122, no. 1, pp. 303-314, 2012.

[8] H. McShane, A. A. Pathan, C. R. Sander et al., "Recombinant modified vaccinia virus Ankara expressing antigen 85A boosts BCG-primed and naturally acquired antimycobacterial immunity in humans," Nature Medicine, vol. 10, no. 11, pp. 1240-1244, 2004.

[9] M. D. Tameris, M. Hatherill, B. S. Landry et al., "Safety and efficacy of MVA85A, a new tuberculosis vaccine, in infants previously vaccinated with BCG: a randomised, placebo-controlled phase 2b trial," The Lancet, vol. 381, no. 9871, pp. 1021-1028, 2013.

[10] K. R. Steingart, N. Dendukuri, M. Henry et al., "Performance of purified antigens for serodiagnosis of pulmonary tuberculosis: a meta-analysis," Clinical and Vaccine Immunology, vol. 16, no. 2, pp. 260-276, 2009.

[11] U. Beyazova, S. Rota, C. Cevheroglu, and T. Karsligil, "Humoral immune response in infants after BCG vaccination," Tubercle and Lung Disease, vol. 76, no. 3, pp. 248-253, 1995.

[12] R. M. Brown, O. Cruz, M. Brennan et al., "Lipoarabinomannanreactive human secretory immunoglobulin A responses induced by mucosal bacille Calmette-Guérin vaccination," The Journal of Infectious Diseases, vol. 187, no. 3, pp. 513-517, 2003.

[13] S. De Vallière, G. Abate, A. Blazevic, R. M. Heuertz, and D. F. Hoft, "Enhancement of innate and cell-mediated immunity by antimycobacterial antibodies," Infection and Immunity, vol. 73, no. 10, pp. 6711-6720, 2005.

[14] A. Casadevall, "Antibody-mediated immunity against intracellular pathogens: two-dimensional thinking comes full circle," Infection and Immunity, vol. 71, no. 8, pp. 4225-4228, 2003.

[15] A. Casadevall, "Antibody immunity and invasive fungal infections," Infection and Immunity, vol. 63, no. 11, pp. 4211-4218, 1995.

[16] A. Casadevall and L.-A. Pirofski, "Immunoglobulins in defense, pathogenesis, and therapy of fungal diseases," Cell Host \& Microbe, vol. 11, no. 5, pp. 447-456, 2012.

[17] H. Nagai, M. Suzukawa, Y. Sakakibara et al., "Immunological responses and epitope mapping by tuberculosis-associated antigens within the RD1 region in Japanese patients," Journal of 
Immunology Research, vol. 2014, Article ID 764028, 8 pages, 2014.

[18] K. Komiya, H. Ariga, H. Nagai et al., "Reversion rates of QuantiFERON-TB gold are related to pre-treatment IFNgamma levels," Journal of Infection, vol. 63, no. 1, pp. 48-53, 2011.

[19] H. Ariga, H. Nagai, A. Kurashima, Y. Hoshino, S. Shoji, and Y. Nakajima, "Stratified threshold values of QuantiFERON assay for diagnosing tuberculosis infection in immunocompromised populations," Tuberculosis Research and Treatment, vol. 2011, Article ID 940642, 9 pages, 2011.

[20] T. Murate, K. Shimokata, A. Watanabe et al., "Chest roentgenogram classification and clinical parameters in patients with active pulmonary tuberculosis," Internal Medicine, vol. 31, no. 2, pp. 185-188, 1992.

[21] K. Komiya, H. Ariga, H. Nagai et al., "Impact of peripheral lymphocyte count on the sensitivity of 2 IFN- $\gamma$ release assays, QFT-G and ELISPOT, in patients with pulmonary tuberculosis," Internal Medicine, vol. 49, no. 17, pp. 1849-1855, 2010.

[22] M. Osada-Oka, Y. Tateishi, Y. Hirayama et al., "Antigen $85 \mathrm{~A}$ and mycobacterial DNA-binding protein 1 are targets of immunoglobulin G in individuals with past tuberculosis," Microbiology and Immunology, vol. 57, no. 1, pp. 30-37, 2013.

[23] M. Legesse, G. Ameni, G. Medhin et al., "IgA response to ESAT-6/CFP-10 and Rv2031 antigens varies in patients with culture-confirmed pulmonary tuberculosis, healthy Mycobacterium tuberculosis-infected and non-infected individuals in a tuberculosis endemic setting, Ethiopia," Scandinavian Journal of Immunology, vol. 78, no. 3, pp. 266-274, 2013.

[24] A. M. M. Mattos, C. S. de Almeida, K. L. M. C. Franken et al., "Increased IgG1, IFN- $\gamma$, TNF- $\alpha$ and IL- 6 responses to Mycobacterium tuberculosis antigens in patients with tuberculosis are lower after chemotherapy," International Immunology, vol. 22, no. 9, pp. 775-782, 2010.

[25] S. Kunnath-Velayudhan, A. L. Davidow, H.-Y. Wang et al., "Proteome-scale antibody responses and outcome of Mycobacterium tuberculosis infection in nonhuman primates and in tuberculosis patients," The Journal of Infectious Diseases, vol. 206, no. 5, pp. 697-705, 2012.

[26] S. Kunnath-Velayudhan, H. Salamon, H.-Y. Wang et al., "Dynamic antibody responses to the Mycobacterium tuberculosis proteome," Proceedings of the National Academy of Sciences of the United States of America, vol. 107, no. 33, pp. 14703-14708, 2010.

[27] A. Zvi, N. Ariel, J. Fulkerson, J. C. Sadoff, and A. Shafferman, "Whole genome identification of Mycobacterium tuberculosis vaccine candidates by comprehensive data mining and bioinformatic analyses," BMC Medical Genomics, vol. 1, no. 1, article $18,2008$.

[28] Y. Yamashita, Y. Hoshino, M. Oka et al., "Multicolor flow cytometric analyses of $\mathrm{CD} 4^{+} \mathrm{T}$ cell responses to Mycobacterium tuberculosis-related latent antigens," Japanese Journal of Infectious Diseases, vol. 66, no. 3, pp. 207-215, 2013.

[29] H. R. Ramage, L. E. Connolly, and J. S. Cox, "Comprehensive functional analysis of Mycobacterium tuberculosis toxin-antitoxin systems: Implications for pathogenesis, stress responses, and evolution," PLoS Genetics, vol. 5, no. 12, Article ID e1000767, 2009.

[30] S. Balu, R. Reljic, M. J. Lewis et al., "A novel human IgA monoclonal antibody protects against tuberculosis," Journal of Immunology, vol. 186, no. 5, pp. 3113-3119, 2011.

[31] A. Williams, R. Reljic, I. Naylor et al., "Passive protection with immunoglobulin A antibodies against tuberculous early infection of the lungs," Immunology, vol. 111, no. 3, pp. 328-333, 2004.

[32] Y. López, D. Yero, G. Falero-Diaz et al., "Induction of a protective response with an IgA monoclonal antibody against Mycobacterium tuberculosis $16 \mathrm{kDa}$ protein in a model of progressive pulmonary infection," International Journal of Medical Microbiology, vol. 299, no. 6, pp. 447-452, 2009.

[33] H.-R. Kim, S. S. Hwang, H. J. Kim et al., "Impact of extensive drug resistance on treatment outcomes in non-HIV-infected patients with multidrug-resistant tuberculosis," Clinical Infectious Diseases, vol. 45, no. 10, pp. 1290-1295, 2007.

[34] E. D. Matos and A. C. M. Lemos, "Association between serum albumin levels and in-hospital deaths due to tuberculosis," International Journal of Tuberculosis and Lung Disease, vol. 10, no. 12, pp. 1360-1366, 2006.

[35] K. Okamura, N. Nagata, K. Wakamatsu et al., "Hypoalbuminemia and lymphocytopenia are predictive risk factors for in-hospital mortality in patients with tuberculosis," Internal Medicine, vol. 52, no. 4, pp. 439-444, 2013.

[36] J.-Y. Wang, L.-N. Lee, and P.-R. Hsueh, "Factors changing the manifestation of pulmonary tuberculosis," The International Journal of Tuberculosis and Lung Disease, vol. 9, no. 7, pp. 777783, 2005.

[37] Ĩ. Comas, J. Chakravartti, P. M. Small et al., "Human T cell epitopes of Mycobacterium tuberculosis are evolutionarily hyperconserved," Nature Genetics, vol. 42, no. 6, pp. 498-503, 2010.

[38] J. Bailey, J. N. Blankson, M. Wind-Rotolo, and R. F. Siliciano, "Mechanisms of HIV-1 escape from immune responses and antiretroviral drugs," Current Opinion in Immunology, vol. 16, no. 4, pp. 470-476, 2004.

[39] D. G. Bowen and C. M. Walker, "Mutational escape from CD8 ${ }^{+}$ T cell immunity: HCV evolution, from chimpanzees to man," Journal of Experimental Medicine, vol. 201, no. 11, pp. 1709-1714, 2005.

[40] M. P. Cooreman, G. Leroux-Roels, and W. P. Paulij, "Vaccineand hepatitis B immune globulin-induced escape mutations of hepatitis B virus surface antigen," Journal of Biomedical Science, vol. 8, no. 3, pp. 237-247, 2001.

[41] C. Scholtissek, "Source for influenza pandemics," European Journal of Epidemiology, vol. 10, no. 4, pp. 455-458, 1994.

[42] B. Raju, Y. Hoshino, I. Belitskaya-Lévy et al., "Gene expression profiles of bronchoalveolar cells in pulmonary TB," Tuberculosis, vol. 88, no. 1, pp. 39-51, 2008.

[43] S. Buccheri, R. Reljic, N. Caccamo et al., "Prevention of the postchemotherapy relapse of tuberculous infection by combined immunotherapy," Tuberculosis, vol. 89, no. 1, pp. 91-94, 2009.

[44] S. Chang-Hong, W. Xiao-Wu, Z. Hai, Z. Ting-Fen, W. Li-Mei, and X. Zhi-Kai, "Immune responses and protective efficacy of the gene vaccine expressing Ag85B and ESAT6 fusion protein from Mycobacterium tuberculosis," DNA and Cell Biology, vol. 27, no. 4, pp. 199-207, 2008.

[45] P. K. Giri, I. Verma, and G. K. Khuller, "Enhanced immunoprotective potential of Mycobacterium tuberculosis Ag85 complex protein based vaccine against airway Mycobacterium tuberculosis challenge following intranasal administration," FEMS Immunology and Medical Microbiology, vol. 47, no. 2, pp. 233241, 2006.

[46] A. Grover, M. F. Ahmed, B. Singh, I. Verma, P. Sharma, and G. K. Khuller, "A multivalent combination of experimental antituberculosis DNA vaccines based on Ag85B and regions of difference antigens," Microbes and Infection, vol. 8, no. 9-10, pp. 2390-2399, 2006. 
[47] K. Huygen, J. Content, O. Denis et al., "Immunogenicity and protective efficacy of a tuberculosis DNA vaccine," Nature Medicine, vol. 2, no. 8, pp. 893-898, 1996.

[48] H. Niu, L. Hu, Q. Li et al., "Construction and evaluation of a multistage Mycobacterium tuberculosis subunit vaccine candidate Mtb10.4-HspX," Vaccine, vol. 29, no. 51, pp. 9451-9458, 2011.

[49] C. Palma, E. Iona, F. Giannoni et al., "The LTK63 adjuvant improves protection conferred by Ag85B DNA-protein primeboosting vaccination against Mycobacterium tuberculosis infection by dampening IFN- $\gamma$ response," Vaccine, vol. 26, no. 33, pp. 4237-4243, 2008.

[50] C. Sánchez-Rodríquez, C. Estrada-Chávez, J. García-Vigil et al., "An IgG antibody response to the antigen 85 complex is associated with good outcome in Mexican Totonaca Indians with pulmonary tuberculosis," International Journal of Tuberculosis and Lung Disease, vol. 6, no. 8, pp. 706-712, 2002.

[51] X. Wu, Y. Yang, J. Zhang et al., "Comparison of antibody responses to seventeen antigens from Mycobacterium tuberculosis," Clinica Chimica Acta, vol. 411, no. 19-20, pp. 1520-1528, 2010.

[52] R. Baumann, S. Kaempfer, N. N. Chegou et al., "Serologic diagnosis of tuberculosis by combining Ig classes against selected mycobacterial targets," The Journal of Infection, vol. 69, no. 6, pp. 581-589, 2014.

[53] S. T. Cole, R. Brosch, J. Parkhill et al., "Deciphering the biology of Mycobacterium tuberculosis from the complete genome sequence," Nature, vol. 393, no. 6685, pp. 537-544, 1998.

[54] A. Geluk, M. Y. Lin, K. E. van Meijgaarden et al., "T-cell recognition of the HspX protein of Mycobacterium tuberculosis correlates with latent $M$. tuberculosis infection but not with $M$. bovis BCG vaccination," Infection and Immunity, vol. 75, no. 6 , pp. 2914-2921, 2007.

[55] A. Purkayastha, L. A. McCue, and K. A. McDonough, "Identification of a Mycobacterium tuberculosis putative classical nitroreductase gene whose expression is coregulated with that of the acr gene within macrophages, in standing versus shaking cultures, and under low oxygen conditions," Infection and Immunity, vol. 70, no. 3, pp. 1518-1529, 2002.

[56] Y. Yuan, D. D. Crane, and C. E. Barry III, "Stationary phaseassociated protein expression in Mycobacterium tuberculosis: function of the mycobacterial $\alpha$-crystallin homolog," Journal of Bacteriology, vol. 178, no. 15, pp. 4484-4492, 1996.

[57] Y. Yuan, D. D. Crane, R. M. Simpson et al., "The 16$\mathrm{kDa} \alpha$-crystallin (Acr) protein of Mycobacterium tuberculosis is required for growth in macrophages," Proceedings of the National Academy of Sciences of the United States of America, vol. 95, no. 16, pp. 9578-9583, 1998.

[58] G. Falero-Diaz, S. Challacombe, D. Rahman et al., "Transmission of $\operatorname{IgA}$ and $\operatorname{IgG}$ monoclonal antibodies to mucosal fluids following intranasal or parenteral delivery," International Archives of Allergy and Immunology, vol. 122, no. 2, pp. 143-150, 2000.

[59] J. Ivanyi, J. A. Morris, and M. Keen, "Studies with monoclonal antibodies to mycobacteria," in Monoclonal Antibodies Against Bacteria, A. J. L. Macario and E. C. Macario, Eds., pp. 59-90, Academic Press, New York, NY, USA, 1985.

[60] N. Ohara, M. Naito, C. Miyazaki, S. Matsumoto, Y. Tabira, and T. Yamada, "HrpA, a new ribosome-associated protein which appears in heat-stressed Mycobacterium bovis bacillus Calmette-Guerin," Journal of Bacteriology, vol. 179, no. 20, pp. 6495-6498, 1997.
[61] G. R. Stewart, L. Wernisch, R. Stabler et al., "Dissection of the heat-shock response in Mycobacterium tuberculosis using mutants and microarrays," Microbiology, vol. 148, part 10, pp. 3129-3138, 2002.

[62] K. A. Wilkinson, G. R. Stewart, S. M. Newton et al., "Infection biology of a novel $\alpha$-crystallin of Mycobacterium tuberculosis: Acr2," Journal of Immunology, vol. 174, no. 7, pp. 4237-4243, 2005.

[63] J. F. Djoba Siawaya, N. B. Bapela, K. Ronacher et al., "Immune parameters as markers of tuberculosis extent of disease and early prediction of anti-tuberculosis chemotherapy response," The Journal of Infection, vol. 56, no. 5, pp. 340-347, 2008. 


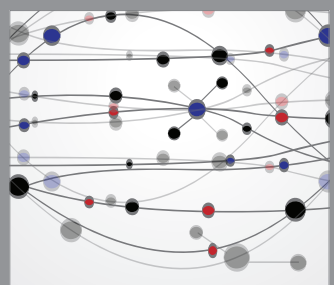

The Scientific World Journal
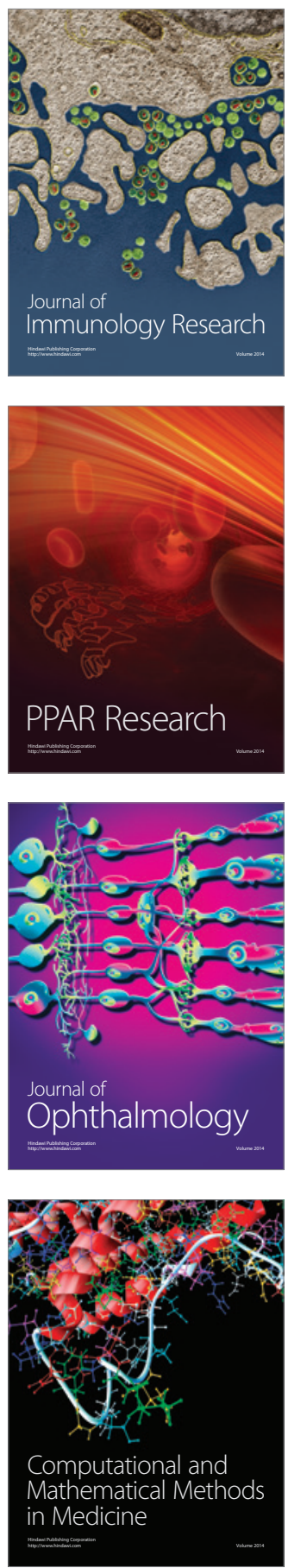

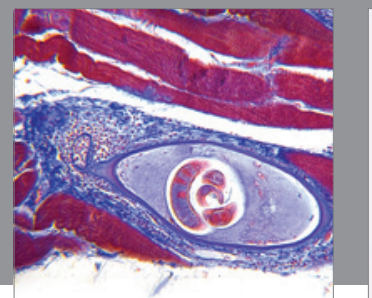

Gastroenterology

Research and Practice
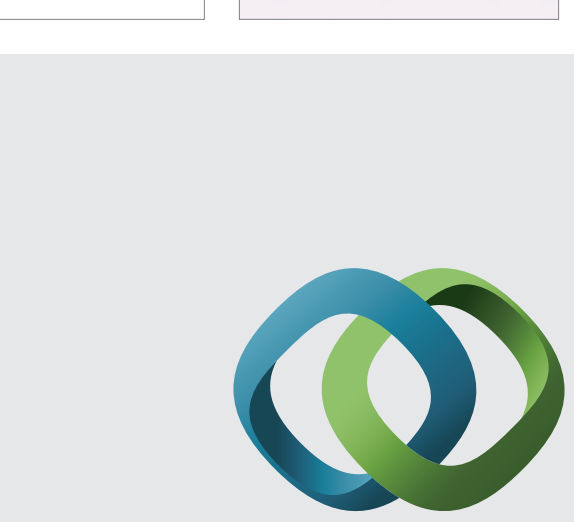

\section{Hindawi}

Submit your manuscripts at

http://www.hindawi.com
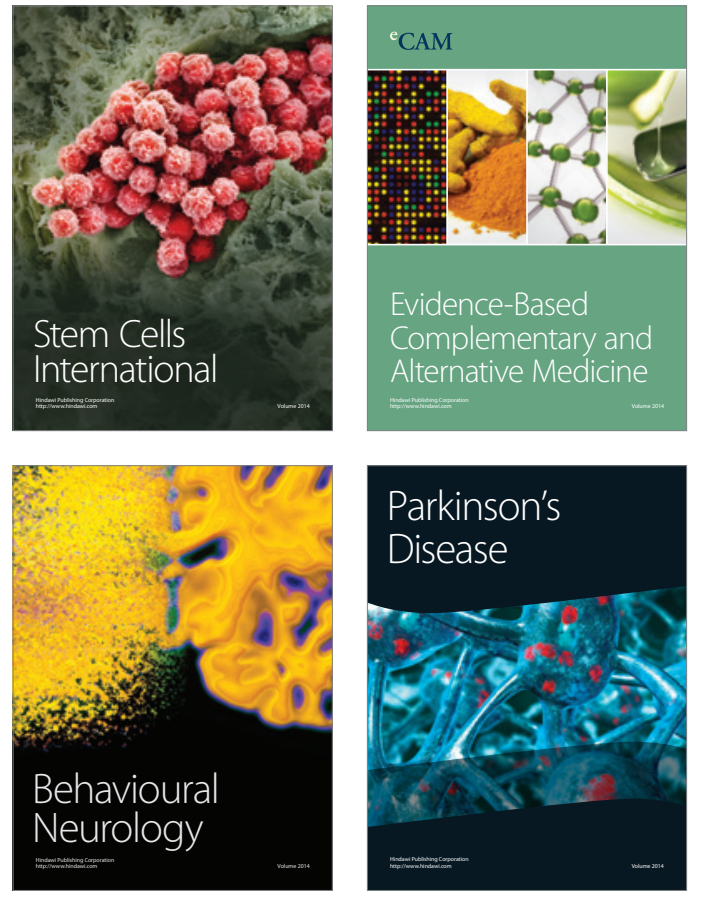
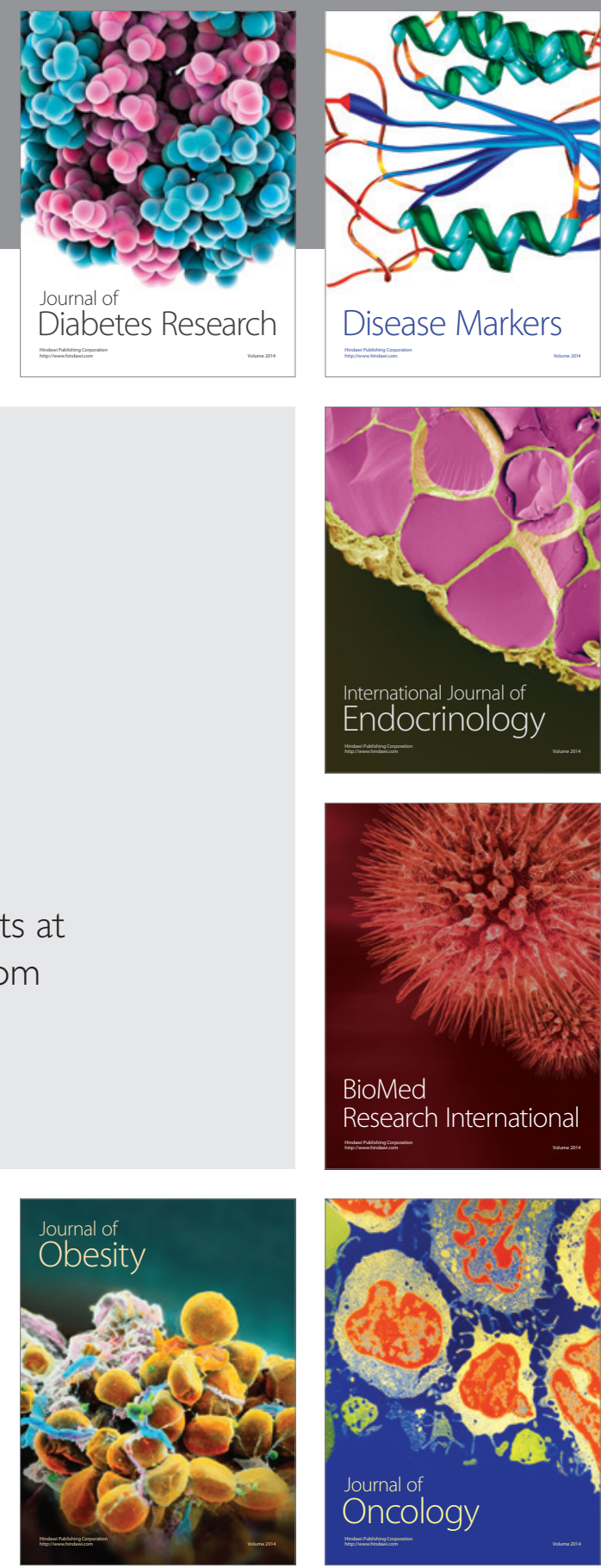

Disease Markers
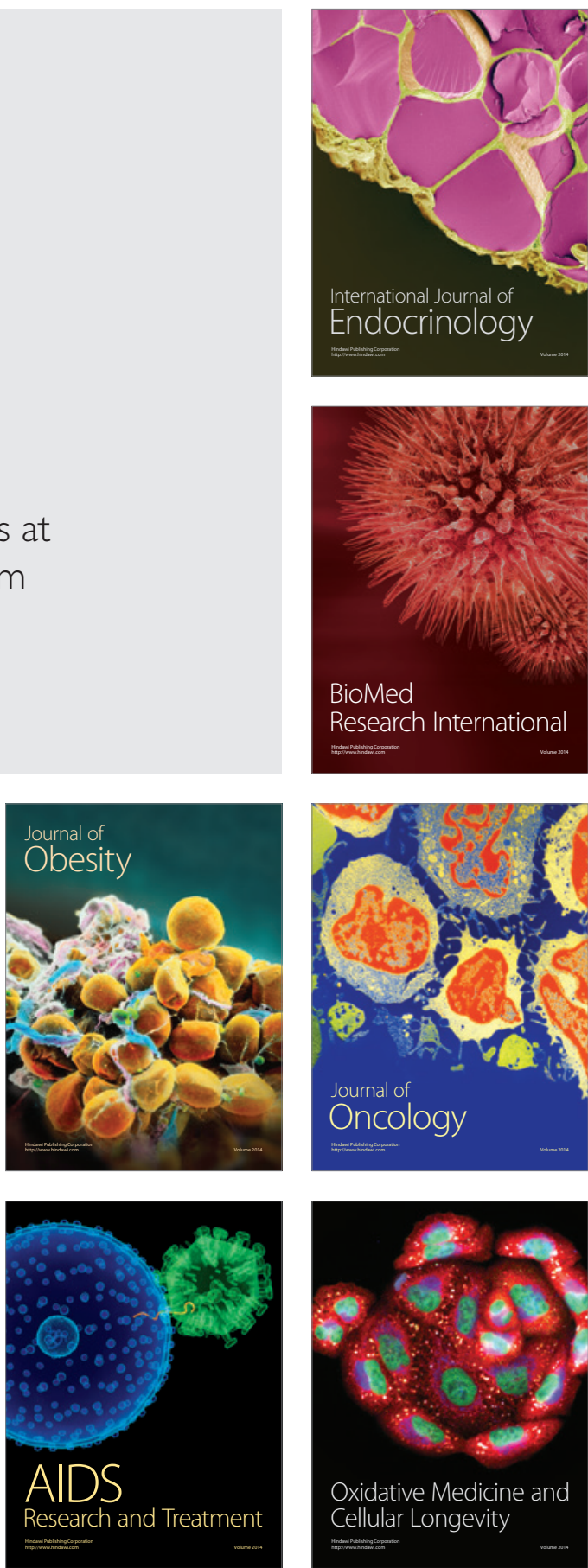